\title{
Laboratory model tests on drainage consolidation performance of drained-timber pile
}

\author{
Xinjun Chaiं ${ }^{* 1, a}$, Chunfeng He $\mathrm{H}^{1, \mathrm{~b}}$ Yifan Xiong $^{1, \mathrm{a}}$, Liming Wu ${ }^{1, a}$, and Peng Zhou ${ }^{1, a}$ \\ ${ }^{1}$ School of Civil \& Architecture Engineering,East China University of Technology, China \\ axj_chai@126.com, bcfhe@ecit.cn,
}

Keywords: Soft clay, consolidation, drained-timber pile, model test.

Abstract. Pine pile is an ancient technology applied in soft ground improvement for more than 1000 years. With the rise of many high-rise buildings, many types of modern mechanized-construction pile are widely developed and applied, for example, steel pile, precast concrete pile, sand pile, gravel pile are widely used instead of timer piles. Yet, in some special conditions, timber piles have a certain advantages due to its environment friendly characteristics, obvious economic benefits and suitability. To overcome the weakness of the traditional pine-pile technology and expand its application in engineering practice, a drained-timber pile technology was put forward, the structure of the drained timber pile was developed in laboratory. The reduced scale mode tests ware carried out to verify the effectiveness of the drained-timber bolt. The test results revealed that under the same loading and consolidation time, the drained-timber bolt can obviously increase the degree of consolidation comparing with traditional timber pile. It can be expected that the drained-timber pile has a good application prospect in the pretreatment of super soft foundation.

\section{Research background}

Pine pile is an ancient technology applied in soft ground improvement for more than 1000 years. Many ancient ruins were excavated and it was found that the pine piles were still remained in good status, which verified that the pine pile has good durability and strong corrosion resistance under water condition[1]

Since 1980s, many modern mechanized construction pile types are widely developed and applied instead of wooden piles. The main reason is that the traditional pine pile has the following two disadvertages in engineering practice of soft ground improvement: 1) the low bearing capacity of pine pile due to the small shear strength of the soft clay; 2) the large post-construction settlement due to the low permeability of the soft clay. The above two problems restrict the extensive application of pine-pile technology[2-5].

To overcome the weakness of the traditional pine pile technology the drained-timber pile technology is put forward by the research group. The main feature of drained-timber pile is that a thin layer geotextile was wrapped around the pine rod, so the excess pore water will be drained through the drained layer while engineering under construction, thus the bearing capacity of the pine pile will be increased and the post-construction settlement will be reduced.

In this study, the structure of the drained-timber pile was developed in laboratory. The reduced scale mode tests ware carried out to verify the effectiveness of the drained-timber bolt[6]. The test results revealed that under the same loading and consolidation time, the drained-timber bolt can obviously increase the degree of consolidation comparing with traditional timber pile. It can be expected that the drained-timber pile has a good application prospect in the pretreatment of super soft foundation.

\section{Test Schematic Design}

Soil Preparation. The soil tested was collected from Diezi Lake of Nanchang city, Jiangxi Province. The main physical and mechanical properties of the soil were listed in Table 1, the soil is a typical soft clay in the Poyang Lake region. 
Table 1 Physical properties of the mucky caly used in the test

\begin{tabular}{cccccccc}
\hline \multirow{2}{*}{ term } & $\begin{array}{c}\text { Natural } \\
\text { density } \\
\rho\end{array}$ & $\begin{array}{c}\text { Water } \\
\text { content } \\
\omega\end{array}$ & $\begin{array}{c}\text { Specific } \\
\text { gravity } \\
\mathrm{G}_{\mathrm{s}}\end{array}$ & $\begin{array}{c}\text { Plastic } \\
\text { limit } \\
\mathrm{PL}\end{array}$ & $\begin{array}{c}\text { Liquid } \\
\text { limit } \\
\text { LL }\end{array}$ & $\begin{array}{c}\text { Plasticity } \\
\text { Index } \\
\text { PI }\end{array}$ & $\begin{array}{c}\text { Liquidity } \\
\text { Index } \\
\text { LI }\end{array}$ \\
\hline unit & {$\left[\mathrm{g} / \mathrm{cm}^{3}\right]$} & {$[\%]$} & - & - & - & - & - \\
\hline Quatity & 1.74 & 90.26 & 2.67 & 26.0 & 52.2 & 26 & 2.47 \\
\hline
\end{tabular}

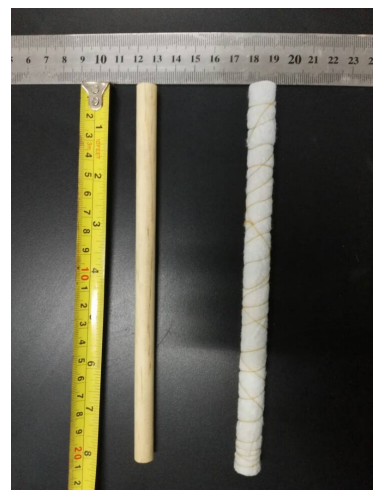

Fig.1 Timber bolt and Drained timber bolt

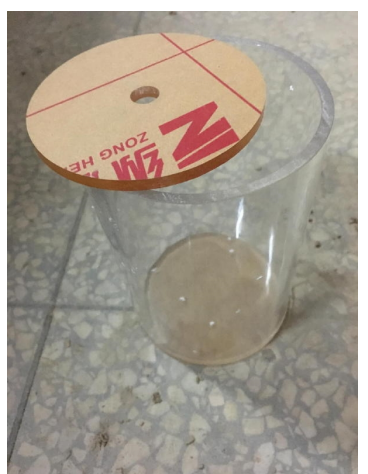

(a)

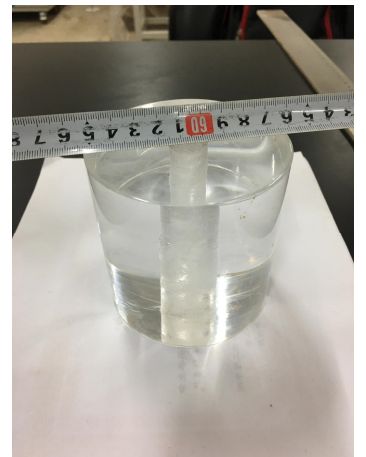

(b)
Fig.2 Plexiglass cylinder (a) and plexiglass hollow transfer column (b)

Drainage Geotextile. The drained geotextile is the main composition of the drained-timber pile, a non-woven geotextile, which is made of $150 \mathrm{~A}$ by the factory with the quality of $150 \mathrm{~g} / \mathrm{cm}^{3}$ and thickness of $1.0 \mathrm{~mm}$, was employed as the drained layer of the drained-timber rod. The permeability coefficient of the geotexitle is about $1 \times 10^{-1} \mathrm{~cm} / \mathrm{s}$, its tearing strength is greater than $0.12 \mathrm{kN}$.

Preparation of timber bolt and drained-timber bolt. In the experiment, the timber bolt is made from the pine rod with a diameter of $10 \mathrm{~mm}$. The compressive strength of the pine rod is $\mathrm{f}_{\mathrm{c}}=12 \mathrm{MPa}$, which meets the requirements of the experimental strength.

The drained-timber bolt is made up of a timber bolt (diameter $10 \mathrm{~mm}$ ) with 2 layers of drainage geotextile wrapped around the timber bolt. The total outer diameter of the drained-timber bolt is about $14 \mathrm{~mm}$. The timber bolt and the drained-timber bolt are shown in Fig. 1

Model Design of Laboratory Soil-Column Consolidation Test. The model laboratory soil-column was composed of plexiglass cylinder, pressure plate, plexiglass hollow transfer column, loading and data monitoring recording system.

Plexiglass cylinder: The plexiglass cylinder, made of plexiglass with thickness of $5 \mathrm{~mm}$, has inner diameter $100 \mathrm{~mm}$ and height $150 \mathrm{~mm}$, the bottom and the side are impervious, as shown in Fig. 2 (a).

The pressure plate: the pressure plate is made of plexiglass with thickness of $5 \mathrm{~mm}$, has a diameter of $98 \mathrm{~mm}$ and a central circular hole with inner diameter of $13 \mathrm{~mm}$. The purpose of the central circular hole is to provide an upward displacement space for the timber bolt (or drained-timber bolt) in the process of loading and consolidation, an shown in Fig.2 (a).

Plexiglass hollow transfer column: The hollow transfer column, made of plexigalss with a height of $90 \mathrm{~mm}$, has a outside diameter $90 \mathrm{~mm}$ and a central hole with inner diameter of $16 \mathrm{~mm}$, as shown in Fig. 2(b).

Design of Two Types of Laboratory Column Consolidation Tests. In order to verify the drainage consolidation performance of the drained-timber bolt, two types of soil-column consolidation tests were designed, which are the soil-column consolidation test for wood bolt (named as Test A) and the soil-column consolidation test for drained-timber bolt (named as Test B). The parameters for both of Test A and Test B were listed in Table 2. The main difference is that for Test B, the drained-timber bolt was used to take place of the timber-bolt of Test A. 


\section{Test Procedures}

Table 2 Set up of two types of consolidation tests in the study

\begin{tabular}{cccccc}
\hline Type of Tests & $\begin{array}{c}\text { Diameter } \\
\text { of bolt }\end{array}$ & $\begin{array}{c}\text { Length } \\
\text { of bolt }\end{array}$ & $\begin{array}{c}\text { Drained } \\
\text { geotextile }\end{array}$ & $\begin{array}{c}\text { Height of } \\
\text { soil column }\end{array}$ & Drained condition \\
\hline Test A & {$[\mathrm{mm}]$} & {$[\mathrm{mm}]$} & & {$[\mathrm{mm}]$} & \\
\hline Test B & 10 & 100 & no & 100 & Vertical only \\
\hline
\end{tabular}

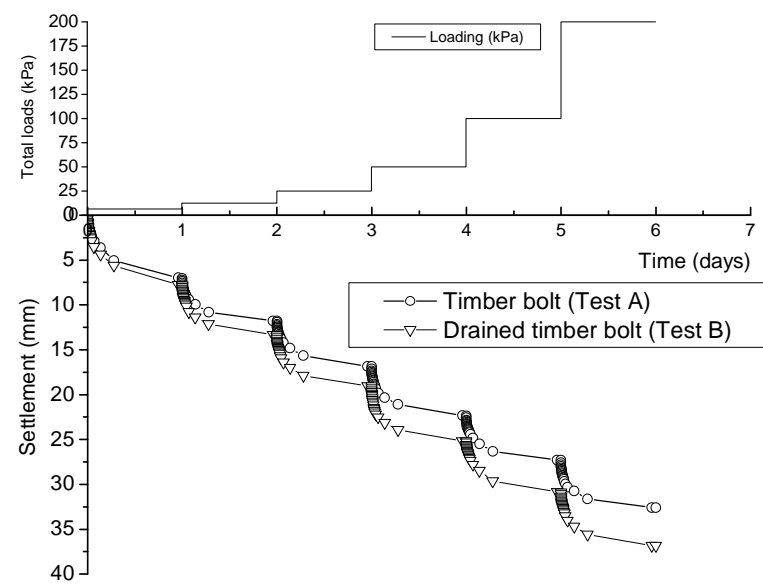

Fig.3 Loading and consolidation settlement vs. time

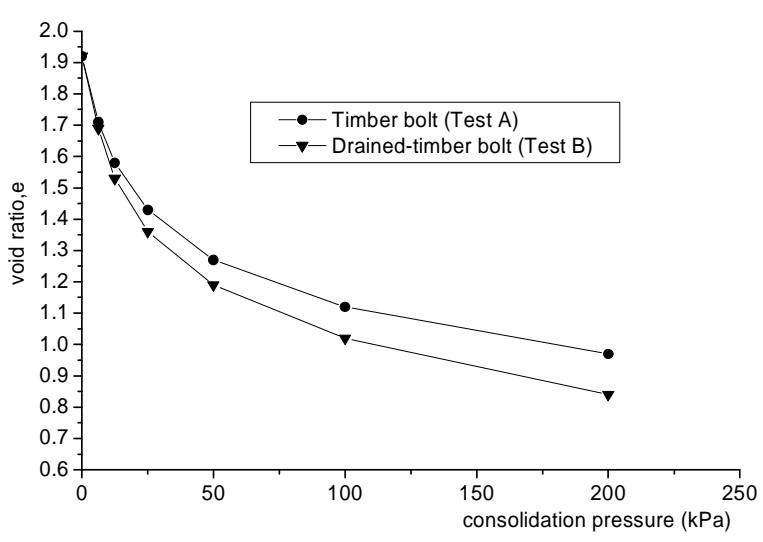

Fig.4 Relations between void ratio vs. Consolidation pressure

Sample Preparation. The test samples were prepared as the following steps: 1) place the soil with initial moisture content of $90 \%$ into the plexiglass cylinder, the soil column is set $100 \mathrm{~mm}$ in height; 2) Insert timber bolt (or drained-timber bolt) vertically into the soil column at the central position and up to the bottom of the cylinder; 3 ) slick the top surface of the soil column, place a piece of permeable geotextile pad on the top surface of the soil column, the geotextile pad has a diameter of $100 \mathrm{~mm}$, a thickness of $3 \mathrm{~mm}$, and a center hole diameter $13 \mathrm{~mm}$; 4) place the pressure plate on the top of the drained pad; 5) place the hollow transfer column on the pressure plate.

Loading Scheme. The loading scheme is designed as 6 steps, which are $6.25 \mathrm{kPa}, 12.50 \mathrm{kPa}, 25 \mathrm{kPa}$, $50 \mathrm{kPa}, 100 \mathrm{kPa}, 200 \mathrm{kPa}$, respectively; each loading step is maintained for 24 hours, and the consolidation settlement with time is monitored and recorded for analysis.

\section{Analysis and Discussion of the Test Results}

Relationship Between the Consolidation Settlement and Time.The relationships of the consolidation settlement with time of the two types of tests are plotted in Fig.3. It shows that: 1) Under the same loading condition, at the end of 6 days consolidation, the final settlements of Test A and Test B were $32.6 \mathrm{~mm}$ and $36.85 \mathrm{~mm}$, respectively, which revealed that the drained geotextile layer of the drained-timber bolt can well play the role of radial drainage; 2) At the initial loading time for each loading step, the settlement rate of Test B is larger than that of Test A, after that, the settlement rate of both of Test $\mathrm{A}$ and Test $\mathrm{B}$ are gradually approaching the same; the phenomenon means that in the initial stages of loading, radial drainage of drained-timber bolt is dominant, with the decrease of excess pore water pressure, the proportion of the degree of consolidation contributed from radial drainage is decreasing; the main reason maybe due to that the height of the soil column is not enough, it can be expected that the contribution of the radial drainage of drained-timber bolt will be 
more clear as the increasing of soil-column height, the conclusion should be investigated by further laboratory model tests.

Relationship of Void Ratio to Consolidation Pressure. The relations of the void ratio vs. consolidation pressure of Test A and Test B are shown in Fig.4, it indicated that under the same load increment and the same consolidation time ( 24 hours), the increment of consolidation settlement of Test $\mathrm{A}$ is always greater than that of the Test $\mathrm{B}$, which reveals that the drainage layer structure of the drained-timber bolt can play the role in improving the consolidation degree of soft clay.

\section{Conclusions}

Aiming to improve the weakness of the traditional pine pile in reinforcing soft clay foundation, the drained-timber pile was developed. Two types of laboratory model tests were carried out to evaluate the effectiveness of the drained-timber pile, the conclusions are made as follows: 1) Under the same loading condition, the drained geotextile layer of the drained-timber bolt can play a well role of radial drainage; 2) In the initial stages of loading, radial drainage of drained-timber bolt is dominant, with the decrease of excess pore water pressure, the proportion of the degree of consolidation contributed from radial drainage decrease; 3 ) it is recommended that the effectiveness and contribution of the drained-timber pile should be evaluated further in a more longer soil column model test; 4) it can be expected that the drained-timber pile will have a prosperous application in small-medium size.

\section{Acknowledgements}

The work described in this paper was supported by the National Natural Science Foundation of China (Grant No.51668002, Grant No.51368002, Grant No.50968001), the Natural Science Foundation (20151BAB206056, 20151BAB206053) of Jiangxi Provincial Department of Science and Technology,the Science and technology support program (20151BBE50014) of Jiangxi Provincial Department of Science and Technology, and the Science and technology project of Jiangxi Provincial Department of Education (GJJ150580). The authors also thank the anonymous reviewers for their comments.

\section{References}

[1] Nanjing Museum, Taizhou Museum: Excavation report of the ancient water gate site in southern Taizhou, Jiangsu Province. Southeast Culture, 2014(1), p.43-52.

[2] Ting Yang, Jian Zhou and Chen Zhou: Analysis and design of timber-pile composite foundation on soft soils. Chinese Journal of Roch Mechanics and Engineerings, 2003,22(9), p.1560-1565.

[3] Weiping Chen:Design and construction of timber piles in soft caly ground. Journal of Guangdong Technical College of Water Resources and Electric Engineering,2005,3(1),p.49-53.

[4] Song bin Yu: Applicaiton of deal pile foundation in Xishalianwei tide gate. Guangxi water resources and Hydropower Engieering, 2005(2),p.25-27.

[5] Jianhui Ao, Honggang Zhai:Application of timber piles in reinforcing the foundation of retaining wall. City Road and Flood Control, 2009(7),p.231-235.

[6] Yifan Xiong: The indoor columnar model experiment on flexibility drainage pile piles reinforcement soft soil foundation. The master degree thesis, 2016. East China University of Technology, Nanchang, Jiangxi Province, China. 